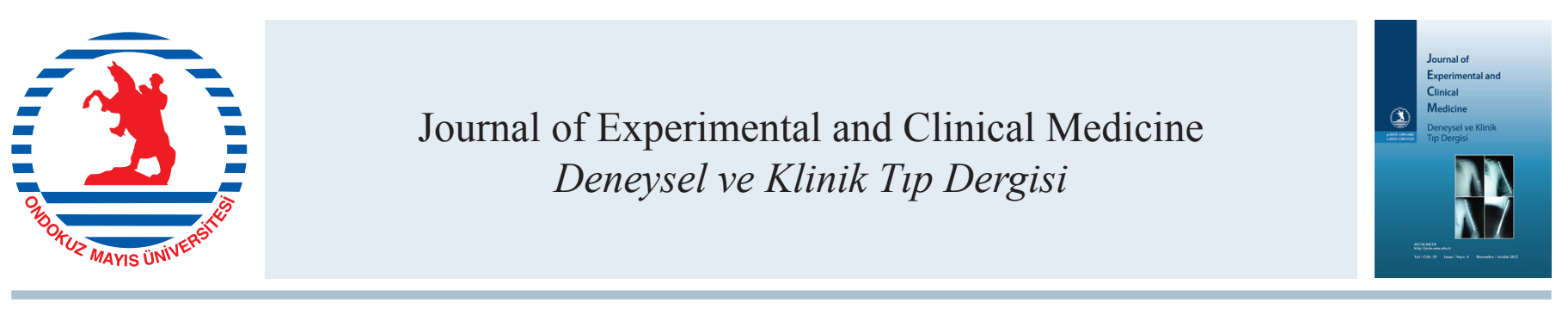

Klinik Araştırma / Clinical Research

doi: $10.5835 /$ jecm.omu.29.04.007

\title{
Humerus diafiz psödoartrozlarının tedavisinde kilitli intramedüller çivileme sonuçları
}

\author{
Locked intramedullary nailing results in treatment of humerus diaphyseal pseudoarthrosis
}

\author{
Yılmaz Şahin*a, Yılmaz Tomakº, Bülent Diri ${ }^{a}$ \\ ${ }^{a}$ Özel Samsun Medicana International Hastanesi, Ortopedi ve Travmatoloji Kliniği, Samsun, Türkiye \\ ${ }^{b}$ Ondokuz Mayıs Üniversitesi, Tıp Fakültesi, Ortopedi ve Travmatoloji Anabilim Dall, Samsun, Türkiye
}

\begin{tabular}{|c|c|}
\hline MAKALE & GILERİ \\
\hline Makale geç & \\
\hline Geliş tarihi & $: 15 / 05 / 2012$ \\
\hline Kabul tarihi & : 06 / 06 / 2012 \\
\hline
\end{tabular}

\section{* Yazışma Adresi:}

Yılmaz Şahin

Özel Samsun Medicana International

Hastanesi Ortopedi ve Travmatoloji Kliniği

55080, Canik, Samsun

E-mail: yilmazfsahin@hotmail.com

\author{
Anahtar Kelimeler: \\ Kırık sabitlenmesi \\ Kilitli intramedüler çivileme \\ Humerus \\ Psödoartroz
}

\section{Keywords:}

Fracture fixation

Locked intramedullary nailing

Humerus

Pseudarthrosis

\section{ÖZET}

Humerus diafiz psödoartrozlarının tedavisinde uyguladığımız kilitli intramedüller çivileme tekniğinin klinik, radyolojik ve fonksiyonel sonuçları değerlendirildi. Çalışmaya, humerus diafiz psödoartrozu tanısıyla kilitli intramedüller çivileme tekniği kullanılarak tedavi edilen 28 hasta (11 erkek, 17 kadın; ort. yaş 50,3; dağılım 26-73 yıl) alındı. Psödoartrozlu vakaların 6'sı hipertrofik, 22'si atrofik psödoartroz tipinde idi. Psödoartrozlu vakaların 12'si sağ, 16's1 sol yerleşimli idi. Psödoartrozlu 28 vakanın 18'i tedavi öncesi ortalama 1,5 (1-3) başarısız ameliyat geçirmiş, 10'u konservatif yöntemlerle tedavi edilmeye çalışılmıştır. Kilitli intramedüller çivileme tüm vakalarda antegrad, açık ve oymalı yöntemle uygulandı. Vakaların hepsine kemik grefti ile grefonaj uygulandı. Fonksiyonel değerlendirme Hunter ve Constant-Murley kriterlerine göre yapıldı. Hastaların ortalama izlem süresi 36,2 ay (dağ 1 lım 7-43 ay) idi. Yirmisekiz psödoartroz vakasının 26'sında takiplerinde kaynama sağlandı. İki vakada kaynama görülmedi. Ortalama kaynama süreleri 16,5 (11-25) hafta idi. Hiçbir vakada cerrahiye bağlı vasküler problem görülmedi. Vakaların birinde ameliyat sonrası radial sinir lezyonu gözlendi ve sinir lezyonunun kendiliğinden iyileşmemesi üzerine hastaya tendon transferi yapıldı. Hastalardan hiçbirinde ön-arka ve yan açılanma yok idi. Radyolojik olarak önemli rotasyonel deformite saptanmadı. Hiçbir vakada cerrahiye bağlı enfeksiyon gelişmedi. Ameliyat sonrası radyolojik değerlendirmede, üç vakada çivi proksimal ucunun yüksekte kaldığı saptandı. Fonksiyonel değerlendirmede Hunter kriterlerine göre 21 vakada mükemmel, 7 vakada iyi; Constant-Murley skoruna göre 22 vakada çok iyi, 6 vakada iyi sonuçlar alındı. Humerus diafiz psödoartrozlarının tedavisinde kilitli intramedüller çivileme ile yeterli fiksasyon ve erken hareket sağlanmakta, tatmin edici klinik, radyolojik ve fonksiyonel sonuçlar alınmaktadır.

J. Exp. Clin. Med., 2012; 29:286-289

\section{ABSTRACT}

The technique of intramedullary nailing in the treatment of pseudarthrosis of the humeral diaphysis clinical, radiological and functional results were evaluated. The study of pseudarthrosis of the humeral diaphysis were treated with the diagnosis of intramedullary nailing technique in 28 patients ( 11 males, 17 females; mean age 50.3, range 26-73 years) were included. Six of these cases were hypertrophic type and 22 of them were atrophic type pseudarthrosis. Twelve of the cases were on the right and 16 were on the left. From 28 cases with pseudarthrosis, 18 had a mean of 1.5 (1-3) failed surgeries and 10 receieved conservative methods before treatment. For all locked intramedullary nailing cases antegrad, front and carved techniques were applied. All patients underwent bone grafting. Functional evaluation was made according to the Hunter's and Constan-Murley's shoulder scoring system. The mean follow-up was 36.2 months (range 7 to 43 months). Twentysix of these 28 cases were succesfully treated and united. Pseudarthrosis was seen in two cases. The average duration of healing 16.5 (11-25) weeks, respectively. None of the cases had surgery-related vascular problems. Radial nerve palsy was observed in one of the cases after surgery and because nerve lesion did not improve Self-tendon transfer was performed on the patient. None of the patients had no anterior-posterior and lateral angulation. There was no significant rotational deformity radiologically. None of the patients developed surgery-related infection. In postoperative radiological evaluation, the proximal tip of the nail was found high in three patients. Functional evaluation according 
to the criteria Hunter 21 cases were excellent, 7 cases were good; Constant-Murley score 22 cases were very good, 6 cases were good. In according to treatment of pseudarthrosis of the humeral diaphyseal intramedullary nailing provided adequate fixation and early motion, satisfying clinical, radiological and functional results are obtained.

J. Exp. Clin. Med., 2012; 29:286-289

\section{Giriş}

Tüm kırıkların \%7'sini humerus kırıkları oluşturmaktadır (Ege, 1989). Humerus diafiz kırıklarından sonra psödoartroz görülme sıklığının \%0-13 arasında olduğu belirtilmiştir (Corley ve ark., 1990; Taylor, 1992). Tarihsel gelişimi boyunca kaynama gecikmesi ve kaynamamanın tedavisi hep tartışmalı olmuştur.

Humerus diafiz psödoartrozlarının tedavisi genel olarak diğer uzun kemik psödoartrozlarının tedavi prensiplerine uygun olarak yapılsa da, alt ekstremite psödoartrozlarındaki gibi kompresif güçlerin etkisinden faydalanma olanağı mevcut olmadığından, burada başarı elde etmek daha zordur. Humerus psödoartrozlarının tedavisinde çeşitli yöntemler kullanılmaktadır. Cerrahi tedavide çeşitli plak vida uygulamaları, intramedüller çivileme ve değişik tipte eksternal fiksatörler, tek başına ya da greftleme yöntemiyle birlikte kullanılmaktadır (Corley ve ark., 1990; Rosen, 1990; Taylor, 1992). Bu çalışmada, değişik nedenlerle oluşmuş 28 humerus diafiz psödoartrozlu vakanın, intramedüller çivileme tekniği ile tedavi sonuçları klinik, radyolojik ve fonksiyonel olarak değerlendirildi.

\section{Araştırma yöntemi}

Ondokuz Mayıs Üniversitesi Tıp Fakültesi Ortopedi ve Travmatoloji Anabilim Dalı ile Samsun Eğitim ve Araştırma Hastanesi Ortopedi ve Travmatoloji Kliniği’nde Aralık 1998Şubat 2011 tarihleri arasında psödoartroz nedeniyle toplam 28 vakaya (11 erkek, 17 kadın; ort. yaş 50,3; dağılım 26-73 yıl) humerus kilitli intramedüller çivi uygulanmıştır. Psödoartrozlu 28 vakanın 6's1 $(\% 21,4)$ hipertrofik, 22'si $(\% 78,5)$ atrofik psödoartroz tipinde idi. Bu 28 vakanın anatomik lokalizasyonuna göre dağılımları ise: 5'i $(\% 17,8) 1 / 3$ proksimal, 21 'i (\%75) 1/3 orta, 2'si $(\% 7,1)$ distal yerleşimli idi. Psödoartrozlu vakaların 12'si $(\% 42,8)$ sağ, 16's1 $(\% 57,1)$ sol yerleşimli idi.

Psödoartrozlu 28 vakanın 18'i $(\% 64,2)$ tedavi öncesi ortalama 1.5 (1-3) başarısız ameliyat geçirmiş, 10'u (\%35,7) konservatif yöntemlerle tedavi edilmeye çalışılmıştır. Psödoartroz nedeniyle opere edilen 28 vakaya açık çivileme uygulanıp, psödoartroz hattındaki fibröz dokular eksize edilip medüller kanal açıldı. Hastalar yarı oturur şezlong pozisyonda opere edildiler. Kilitli intramedüller çivileme tüm olgularda antegrad, açık ve oymalı yöntemle uygulandı. Fiksasyonun stabil olduğu düşünülerek hastalara ameliyat sonrası breys gibi destek cihazları kullanılmadı.

Subakromiyal sıkışma oluşmaması için çivi proksimal ucunun kıkırdak altına tam inecek şekilde sonlandırılması hedeflenerek çivinin rotator manşetin altında kalmasına dikkat edildi.

Psödoartroz hattının kaynadığına, klinik olarak muayenede kırık hattında ağrı olmayışı ve radyolojik olarak sağlam ve devamlı kallus köprüsü oluştuğunun görülmesiyle karar verildi. Fonksiyonel değerlendirme, omuz/dirsek hareket ge- nişliği ve günlük aktivitelerde ekstremitenin kullanımı göz önüne alınarak Hunter ve Constant-Murley kriterlerine göre değerlendirildi (Hunter, 1992; Pogliacomi ve ark., 2008).

\section{Sonuçlar}

Psödoartrozlu 28 vakanın 2'sinde $(\% 7,1)$ kaynama elde edilemedi. Psödoartrozlu vakaların ortalama izlem süresi 36,2 (7-43) ay idi. Psödoartroz nedeniyle opere edilen 28 vakaya açık çivileme uygulanıp psödoartroz hattındaki fibröz dokular eksize edilip medüller kanal açıldı ve bu olgularda ortalama kaynama süresi 16,5 (11-25) hafta olarak bulundu. Vakaların hepsinde $(\% 100)$ humerus cismine oyma işlemi uyguland.

Ameliyat komplikasyonu olarak psödoartrozlu bir $(\% 3,5)$ vakada radial sinir lezyonu gelişmiş, 6 ay sonra iyileşme bulgularının görülmemesi üzerine yapılan tendon transferi ile mükemmel fonksiyonel sonuç elde edilmiştir. Hiçbir olguda vasküler patoloji gelişmedi. Psödoartrozlu bir $(\% 3,5)$ vakada ameliyat esnasında çivi yerleştirilirken iyatrojenik olarak suprakondiler kırık gelişmiş ve interfragmanter vida ile fiksasyon sağlanmıştır. Bu olgunun son kontrolünde omuz ve dirsek fonksiyonlarının tam olduğu ve kaynama sağlandığ görülmüştür. Ameliyat sonrası radyolojik değerlendirmede, $3(\% 10,7)$ vakada çivi proksimal ucunun yüksekte kaldığ saptandı ve bu vakaların birinde ağrı nedeniyle kaynamayı takiben çivi çıkarıldı. Bu vakada tespit materyali çıkarıldıktan sonra ağrının düzeldiği, mevcut olan hareket kısıtlılığının da büyük oranda ortadan kalktığı gözlendi. Hastalardan hiçbirinde ön-arka ve yan açllanma yok idi. Radyolojik olarak önemli rotasyonel deformite saptanmadi.

Son kontrollerde omuz ve dirsek fonksiyonel değerlendirme sonuçları; Hunter skorlamasında 21 (\%75) vakada mükemmel olup, 7 (\%25) vakada iyi olarak bulunmuştur. Constant-Murley omuz ve dirsek fonksiyonel değerlendirme sonuçları; $22(\% 78,5)$ vakada çok iyi, $6(\% 21,4)$ vakada iyi olarak değerlendirilmiştir.

\section{Tartışma}

Humerus psödoartrozlarının tedavisi zor ve zahmetlidir. Uygulanan cerrahi girişim sayısı arttıkça başarı oranı azalmaktadır. Humerus psödoartrozlarının tedavisinde uygulanan intramedüller çivileme yönteminin başarı oranı literatür araştırması yapıldığında ortalama \%54-87 olarak belirtilmiştir (Karaoğlu, 2001).

Chi-Chuan Wu (2009), 32 humerus psödoartrozlu hastay1 Seidel intramedüller kilitli çivi ile tedavi etmiş ve ortalama 5 (3-7) ayda kaynama gerçekleşmiştir. Hiçbir hastasında komplikasyon gelişmemiştir. Yazara göre humerus psödoartrozlarında intramedüller kilitli çiviler, kemik grefti ile veya kemik greftsiz olarak kullanılabilir ve sonuçları da oldukça başarılıdır. Chi-Chuan Wu, Seidel intramedüller kilitli çivi uyguladığı hastalarının hepsinde koruyucu destek cihazları kullanmıştır. 

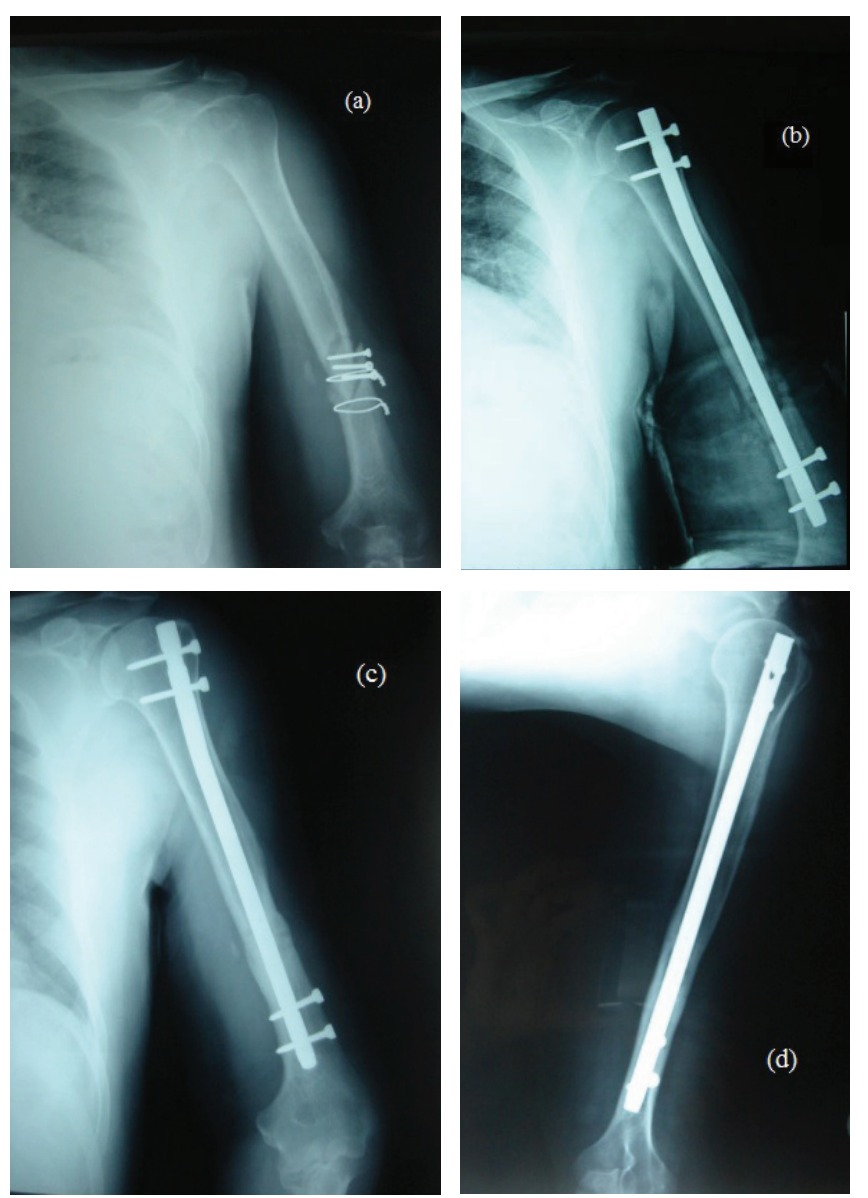

Şek. 1. Sol humerus diafiz 1/3 orta-distal bileşke psödoartrozunun (a) ameliyat öncesi, (b) ameliyat sonrası, (c,d) geç dönem (19. ay) grafileri.
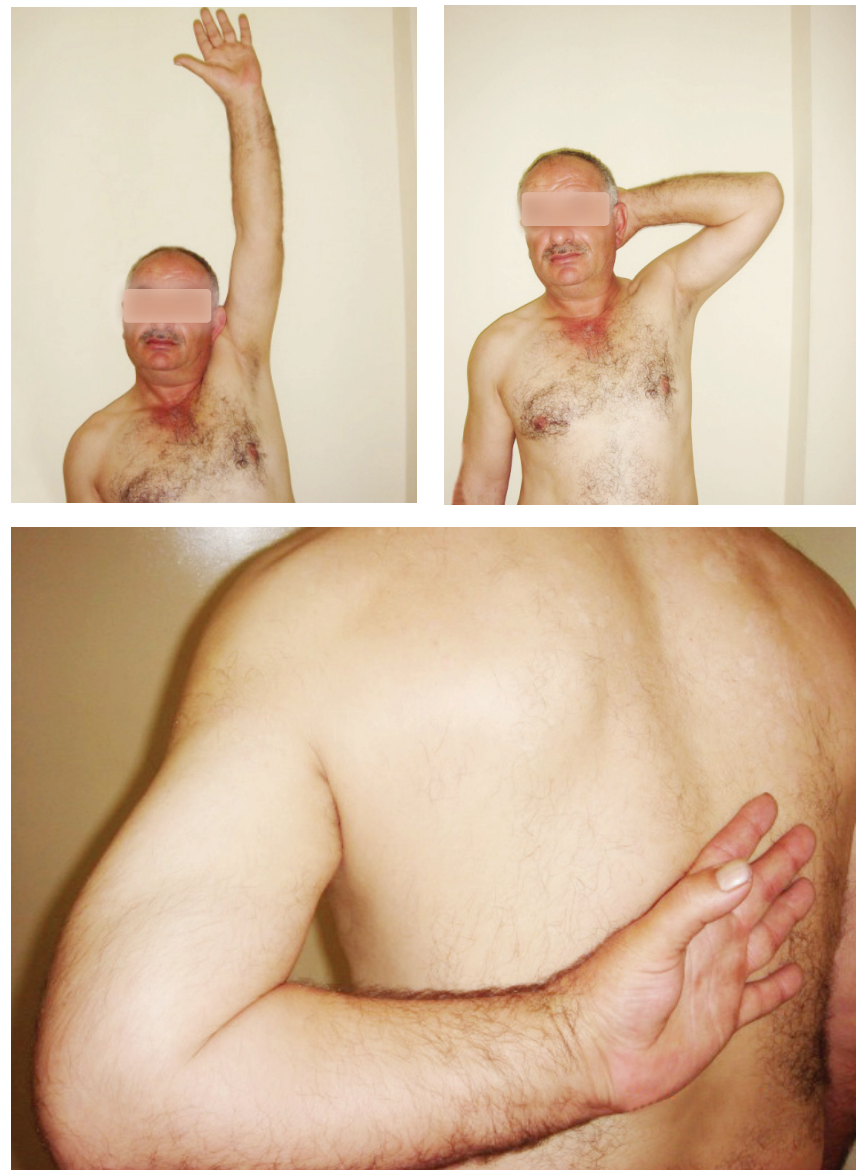

Şek. 2. Son kontroldeki omuz ve dirsek hareket genişliği
Plak vida uygulamasının çok yaygın olarak kullanılmasına rağmen yazara göre, geniş yumuşak doku diseksiyonu gerektirmesi, plak uygulaması esnasında radial sinir lezyonu riskinin olması ve çevre yumuşak dokularda ameliyata bağl1 yapışıklıkların olması gibi sakıncaları vardır. İntramedüller çivilerin, radial siniri yaralama riskinden uzak olmasının avantaj fakat rotasyonel stabilitenin sağlanamaması yönünden dezavantaj olduğunu belirtmiş ve bu sorun kırık hattına U çivisi çakılarak çözülmeye çalışılmıştır. Vakalarında kullandığ 1 Seidel çivisinin kilitli olmasının rotasyonel stabiliteyi temin ettiğini belirtmiştir. Çalışmamızda Seidel çivisi ile tedavi edilen olgu yoktur. Literatür gözden geçirildiğinde Seidel çivisi ile tedavi sonrasında rotasyonel problemler, kırık hattında ayrılma ve çivinin çıkarılma problemleri bildirilmiştir (Riemer ve ark., 1994; Svend-Hansen ve ark., 1998).

Lin ve ark. (2000) humerus diafizinde kaynama gecikmesi ve kaynamama nedeni ile 41 vakaya kilitli intramedüller çivi uygulamıştır. On üç vaka kaynama gecikmesi, 28 vaka kaynamama nedeniyle opere edilmiştir. Bu vakalardan 39 vakaya açık, 2 vakaya kapalı teknik uygulanmıştır. Açık teknik uygulanan bütün vakalarda kemik grefti kullanılmıştır. Kaynama süresini ortalama 5,6 ay olarak bildirmişlerdir. Bizim çalışmamızda kaynama süresi 16,5 hafta olarak bulunmuştur. Biz bu kaynama süresinin, granülasyon dokularının iyi temizlenmesi, çepeçevre dekortikasyon işleminin yapılması, medüller kanalın titizlikle açılması ve greftlemeyle ilgili olduğunu düşünmekteyiz.

Gupta ve ark. humerus psödoartrozlu hastalarda açık olarak yaptıkları intramedüller çivileme uygulamaları ile 5-7 ayda \%89 oranında kaynama elde etmişlerdir. Hastalarının hepsinde koruyucu breys uygulamışlardır (Gupta ve ark., 1985). Bizim çalışmamızda da sonuçlar literatür ile benzer olup \%92,8 oranında kaynama elde edilmiştir. İki vakamızda $(\% 7,1)$ psödoartroz görülmüştür.

Ilyas ve ark. (2003) 27 humerus diafiz psödoartroz vakasında kilitli intramedüller çivileme uygulamışlardır. Vakaların 12'sinde açık olarak, 15 'inde kapalı olarak uygulanmıştır. Açık olarak uygulanan vakaların hepsinde otojen kemik greftlemesi kullanılmıştır. Yine vakaların hepsinde oymalı teknik kullanılmıştır. Vakaların 15'i 3-6 ay arasında kaynamıştır. Yine vakaların 12'sinde en az 6 ayda hiç kaynama elde edilemediği için ilave cerrahiye ihtiyaç olmuştur. Komplikasyon olarak 1 hastada oyma işlemi esnasında iyatrojenik kırık olmuş, bununla beraber 2 vakada geçici radial sinir felci, 1 vakada geçici ulnar sinir felci görülmüş ve kendiliğinden düzelmiştir. Başarı oranını \%56 olarak bulmuşlar ve rijidite ve kompresyonun problemli olduğunu söylemişlerdir.

Çivi çapının medulla genişliğini doldurduğu, kilitleme vidalarının her iki korteksi tam olarak tuttuğu olgularda rijit fiksasyon sağlayacağını düşünüyoruz. Psödoartroz bölgesinde kompresyon sağlamak için ya kompresyona olanak tanıyan çiviler kullanılmalı, ya da distal vidalar uygulandıktan sonra çivinin çıkarma aparatı takılıp çivi çıkarılacakmış gibi yukar1 doğru çektirilmelidir. Bu sayede psödoartroz bölgesindeki distraksiyon düzelecektir. Burada dikkat edilmesi gereken nokta, eğer çıkarma aparatının yukarı çekilmesi ile distraksiyon düzeltilecekse, başlangıçta çivinin biraz daha fazla kemiğe gömülmesi gerekmektedir, aksi takdirde çivi proksimal ucunun normalden yukarıda kalıp fonksiyonel problem yapabileceğidir. İşlem sonunda çivi üst ucunun çıkıntı yapmamış olduğundan emin olunmalıdır. Çalışmamızda vakalarımızın hepsinde $(\% 100)$ humerus diafizine oyma işlemi uygulandı. 
Psödoartrozlarda oyma işleminin oldukça önemli ve gerekli olduğu görüşündeyiz. Bu sayede intramedüller kanal iyice açılarak internal greftleme yapılabildiği gibi, daha geniş çaplı çivi ile daha güçlü fiksasyon da elde edilmiş olacaktır. Psödoartroz olgularından 1'inde $(\% 3,5)$ ameliyat esnasında çivi çakılırken iyatrojenik olarak suprakondiler kırık gelişmiş ve interfragmanter vida ile fiksasyon sağlanmıştır. Bu vakanın son kontrolünde omuz ve dirsek fonksiyonlarının tam olduğu ve kaynama ile sonuçlandığı görülmüştür. Bir $(\% 3,5)$ vakamızda ise, radial sinir lezyonu gelişip 6 ay sonra iyileşme bulgularının görülmemesi üzerine yapılan tendon transferi ile mükemmel fonksiyonel sonuç elde edilmiştir.

Bazı yazarlar kaynamama nedenli kırıklarda oymalı intramedüller çivilemeyi veya kemik grefti ve kompresyon plağ 1 ile fiksasyonu önermektedirler. Aseptik, vasküler ve 1/3 orta humerus diafiz kırıklarının kaynamama komplikasyonunda tercih edilebilecek en uygun yöntemin kapalı, oymalı kilitli intramedüller çivileme olduğunu, avasküler veya kemik kaybı olan proksimal ve distal kırıkların kaynamama komplikasyonunda ise kemik grefti ve kompresyon plağı ile tedavinin daha uygun olacağını önermektedirler (Zuckerman ve Koval, 1996). Biz iki kilitleme vidasının her iki korteksi tam olarak tutabildiği, yumuşak doku problemi ve enfeksiyonu olmayan $1 / 3$ proksimal ve $1 / 3$ distal dahil tüm diafiz psödoartrozlarında intramedüller çivilemenin uygun tercih olduğunu düşünüyoruz.

Humerusa antegrad kilitli intramedüller çivi uygulamas1 ile ilgili çekinceleri olanların vurguladıkları temel konu omuz problemleridir. Kumar ve Sadiq, (2002) humerus kilitli intramedüller çivileme sistemi kullanılan vakalarda omuz disfonksiyonu, osteoporotik hastalarda çivi migrasyonu gibi problemler bildirmişlerdir. Crates ve Whittle, (1998), hume- rus antegrad çivileme ile başarılı sonuç elde edilebilmekle birlikte, bu bulguların sonucunda da omuz fonksiyonlarında azalma ortaya çıkabileceğini bildirmişlerdir. Bizim deneyimimize göre, çivi uygulanırken bir teknik hata olarak çivi üst ucu kıkırdak seviyesi ve üzerinde kalmamışsa, rotator manşet kapatma sırasında normal anatomisine uygun kapatılmışsa ve erken dönemde omuz eklem hareketlerine başlanmışsa herhangi bir fonksiyonel kusur yaşanmayacaktır. Aksine çivi üst ucunun kıkırdak seviyesinin üzerine çıkması ise, omuzda düzeltmesi güç fonksiyonel ve anatomik kusurlara yol açmaktadir.

Psödoartroz tedavisinde başarılı bir cerrahi sonucun anahtarı, minimal yumuşak doku hasarı ve yeterli fakat en az metalik cihaz kullanımı gerektiren rijit fiksasyondur. Kilitli intramedüller çivilemenin diğer cerrahi tedavilere göre belirgin üstünlükleri vardır. Fiksasyon materyalinin mekanik olarak daha güçlü olması, implant yetmezliği sorunlarının çok ender görülmesi, ameliyat sonrası dönemde alçı, atel, breys gibi eksternal tespit gereçlerine ihtiyaç duyulmaması, yumuşak doku hasarı az olduğu için kanlanmanın daha fazla olması ve bunun sonucu kırı iyileşmesinin hızlanması, erken hareket verilebildiğinden daha iyi fonksiyonel sonuçlar ve erken işe dönmeye olanak tanıması, yapılan minimal insizyon sonucu kanama miktarı ve ameliyat süresinin kısa olması, enfeksiyon oranının düşük olması, açısal deformite derece ve sıklı̆ğının az olması yöntemin önemli üstünlükleridir. Tüm bu avantajlarının yanında, kilitli intramedüller çivileme rijit fiksasyon nedeniyle rotasyonel deformitelerin olmaması, stabilizasyonun iyi olması, yüksek kaynama oranları ve kısa kaynama süreleri ile humerus diafiz psödoartrozlarının tedavisinde öncelikli olarak tercih edilecek bir tedavi yöntemi olarak karşımıza çıkmaktadır.

\section{KAYNAKLAR}

Chi-Chuan Wu MD, 1996. Humeral Shaft Nonunion Treated by a Seidel Interlocking Nail with a Supplementary Staple. Clinical Orthopaedics and Related Research. 326, 203-208.

Corley, F.G., Williams, G.R., Pearce, J.C., Rockwood, C.A. Jr, 1990. The management of nonunions of the humerus. Instr. Course Lect. 39, 277-288.

Crates, J., Whittle, A.P., 1998. Antegrade interlocking nailing of acute humeral shaft fractures. Clin. Orthop. Relat. Res. 350, 40-50.

Ege, R., 1989: Kırıklar, eklem yaralanmaları. Travmatoloji kitabı. Kadığlu matbaası, Ankara. 25-63.

Gupta, R.C., Gavr, S.C., Tiwazi, R.C., 1985. Treatment of ununited fractures of the shaft of the humerus with bent nail. Injury. 16, $276-280$.

Hunter, S.G., 1992. The closed treatment of fractures of the humeral shaft. Clin. Orthop. 164, 192-198.

Ilyas, I., Younge, D.A., 2003. Locked intramedullary nailing for difficult nonunions of the humeral diaphysis. Int. Orthop. 27, $278-281$.

Karaoğlu, A., 2001. Humerus diafiz psödoartrozlarında cerrahi tedavi metodlarının karşılaştırılması. İstanbul Üniversitesi Tıp Fakültesi Uzmanlık tezi. İstanbul. 77.

Kumar, A., Sadiq, S.A., 2002. Non-union of the humeral shaft treated by internal fixation. Int. Orthop. 26, 214-216.

Lin, J., Hou, S.M., Hang, Y.S., 2000. Treatment of humeral shaft delayed unions and nonunions with humeral locked nails. J. Trauma. 48, 695703.

Pogliacomi, F., Devecchi, A., Costantino, C., Vaienti E, 2008. Functional long-term outcome of the shoulder after antegrade intramedullary nailing in humeral diaphyseal fractures. Chir. Organi Mov. 92, 11-16.

Riemer, B., Foglesons, M., Burke, C., Butterfield, S., 1994. Complications of Seidel intramedullary nailing of narrow diameter humeral diaphyseal fractures. Orthopedics 17, 19-29.

Rosen, H., 1990. The treatment of nonunions and pseudarthrosis of the humeral shaft. Orthop. Clin. North Am. 21, 725-742.

Svend-Hansen, H., Skettrup, M., Rathcke, M.W., 1998. Complications using the intramedullary humeral nail: outcome in 31 patients. Acta Orthop. Belg. 64, 290-295.

Taylor, 1992. Delayed union and nonunion of fractures. In: Campbell's operative orthopaedics. Vol. 2, 8th ed. Crenshaw AH, editör. St. Louis: Mosby Year Book. 1287-1345.

Zuckerman, J.D., Koval, K.J., 1996. Fractures of the Shaft of the Humerus. Rockwood and Green's Fractures in Adults. 4th Edition Philedalphia. Lippincott. 1, 1025. 